\title{
Características morfogênicas, estruturais e acúmulo de forragem do capim- tanzânia submetido a duas alturas e três intervalos de corte ${ }^{1}$
}

\author{
Karine da Silva Pena ${ }^{2}$, Domicio do Nascimento Júnior ${ }^{3}$, Sila Carneiro da Silva ${ }^{4}$, Valéria \\ Pacheco Batista Euclides ${ }^{5}$, Anderson de Moura Zanine ${ }^{2}$
}

1 Pesquisa financiada pela CAPES e pelo CNPq.

2 Programa de Pós-graduação em Zootecnia da Universidade Federal de Viçosa, Campus UFV, Viçosa, MG, CEP: 36570-000

3 Departamento de Zootecnia da Universidade Federal de Viçosa, Campus UFV, Viçosa, MG, CEP: 36570-000.

4 Departamento de Zootecnia da Escola Superior de Agricultura "Luiz de Queiroz", Campus ESALQ, Piracicaba, SP,CEP: $13418-900$.

${ }^{5}$ Embrapa Gado de Corte, Embrapa Gado de Corte, Caixa Postal 154, Campo Grande, MS, CEP: 79002-970.

RESUMO - Avaliaram-se as características morfogênicas e estruturais e o acúmulo de forragem do capim Panicum maximum, cv. Tanzânia, submetido a duas alturas de corte $(25$ e $50 \mathrm{~cm}$ ) e três intervalos de corte (correspondentes ao surgimento de duas, três e quatro folhas por perfilho). Utilizou-se um arranjo fatorial $2 \times 3$ em delineamento de blocos completos casualizados, com três repetições. A taxa de aparecimento de folhas diminuiu e o filocrono aumentou com a redução da frequência de desfolhação. De modo geral, o comprimento final da folha foi menor na altura de corte $25 \mathrm{~cm}$ que na de $50 \mathrm{~cm}$. A taxa de senescência de folhas e a taxa de alongamento de colmos tenderam a aumento quando o intervalo de corte variou de duas para três folhas por perfilho. A taxa de mortalidade de perfilhos aumentou ao longo do período de avaliação. As altas taxas de mortalidade e de aparecimento de perfilhos caracterizaram um padrão intenso de renovação (turnover) da população de perfilhos. A altura pré-desfolhação diminuiu com o aumento da frequência de corte, enquanto a massa de forragem tendeu a ser maior nas menores frequências de corte. O acúmulo de colmos só variou entre as alturas de corte no segundo corte e foi menor no intervalo de duas folhas em comparação aos de três e quatro folhas surgidas por perfilho, também no mesmo corte. O intervalo de cortes do capim-tanzânia não deve exceder o tempo necessário para o aparecimento de duas a três folhas por perfilho.

Palavras-chave: altura de corte, estrutura, número de folhas, perfilho

\section{Morphogenic and structural characteristics and herbage accumulation of Tanzania grass submitted to two cutting heights and three intervals}

\footnotetext{
ABSTRACT - The morphogenetic and structural characteristics and herbage accumulation were assessed of Panicum maximum cv. Tanzania subjected to two cutting heights $(25$ and $50 \mathrm{~cm}$ ) and three cutting intervals (corresponding to the appearance of two, three and four leaf per tiller). A $2 \times 3$ factorial arrangement was used in a randomized complete block design with three replications. Leaf appearance rate decreased and phyllochron increased with low cutting frequency. In general, the final leaf length was shorter for the $25 \mathrm{~cm}$ compared to the $50 \mathrm{~cm}$ cutting height. Rates of leaf senescence and stem elongation tended to increase as cutting interval increased from two to three new leaves produced per tiller. Tiller mortality rate increased throughout the experimental period, and the high rates of tiller appearance and death indicated an intense turnover in tiller population. The pre-defoliation hight decreased with increase in cutting frequency, while the herbage mass tended to be greater in hte smaller cutting frequencies. Stem accumulation differed between cutting heights only at the second cut and was smaller for the two leaf than for the three and four leaf per tiller cutting intervals for the same second cut. The cutting interval of Tanzania grass should not exceed the time necessary to ensure the appearance of two to three leaves per tiller.
}

Key Words: cutting height, number of leaves, structure, tiller

Este artigo foi recebido em 20/1/2008 e aprovado em 27/11/2008. 


\section{Introdução}

Os entraves da produção animal baseada no uso de plantas forrageiras tropicais podem, em parte, ser reduzidos por meio de práticas de manejo que aumentem a produção e a eficiência de utilização do pasto. O estudo da morfogênese, definida como a origem e o desenvolvimento dos órgãos num organismo, da sucessão de eventos determinantes da produção, expansão e forma da planta no tempo e no espaço tem sido essencial para que esse objetivo seja atingido (Lemaire \& Chapman, 1996; Sattler \& Rutishauser, 1997). A morfogênese, em um pasto vegetativo, pode ser descrita por três características básicas: o aparecimento de folhas, o alongamento de folhas e a duração de vida da folha. A combinação dessas variáveis morfogênicas básicas é responsável pelas principais características estruturais do pasto: tamanho da folha, densidade populacional de perfilhos e número de folhas vivas por perfilho.

A avaliação de características morfogênicas, por sua relação com a estrutura do pasto, surge como alternativa para definir estratégias de manejo visando melhoria da eficiência de utilização da pastagem, bem como de sua persistência. O momento da desfolhação baseado no intervalo de aparecimento de folhas em perfilhos individuais (filocrono) e no número constante de folhas por perfilho foi proposto por Grant et al. (1988), Fulkerson \& Slack (1995) e Gomide (1997) como uma possível estratégia de manejo. Nesse contexto, a morfogênese, ecofisiologia e ecologia do pastejo passaram a assumir papéis cada vez mais importantes no sentido de permitir o desenvolvimento e a compreensão mais detalhada de processos de crescimento, possibilitando o estabelecimento de relações de causa e efeito mais precisas entre ações de manejo e as respostas de produção das pastagens, premissa básica para a idealização e condução de sistemas eficientes de produção animal em pastagens (Da Silva, 2009). Os resultados dos experimentos conduzidos segundo essa filosofia de pesquisa têm permitido o estabelecimento de metas claras de condição de pasto capazes de possibilitar o ajuste e a definição de estratégias eficientes e eficazes de manejo do pastejo. Existe, portanto, a necessidade de se estabelecer estratégias mais racionais de manejo da desfolhação que não prejudiquem a produção, persistência e produtividade das plantas forrageiras.

No Brasil, grande proporção das áreas de pastagens cultivadas é formada pelo capim-tanzânia (Panicum maximum cv. Tanzânia) (Aronivich, 1995). Apesar da abrangência e dimensão das áreas cultivadas com essa planta forrageira, pouco se conhece a respeito de sua ecofisiologia e dos padrões de crescimento e desenvolvimento. O objetivo neste estudo foi avaliar as características morfogênicas e estruturais e o processo de acúmulo de forragem de Panicum maximum cv. Tanzânia submetido a duas alturas e a três intervalos de corte.

\section{Material e Métodos}

O experimento foi realizado no Departamento de Zootecnia da Universidade Federal de Viçosa, Viçosa, Minas Gerais (latitude $20^{\circ} 45^{\prime}$ S, longitude $42^{\circ} 51^{\prime}$ W e altura $651 \mathrm{~m}$ ), no período de dezembro de 2004 a abril de 2005. A precipitação pluviométrica total no período experimental foi de $1.340 \mathrm{~mm}$ e a temperatura média anual foi $19^{\circ} \mathrm{C}$,

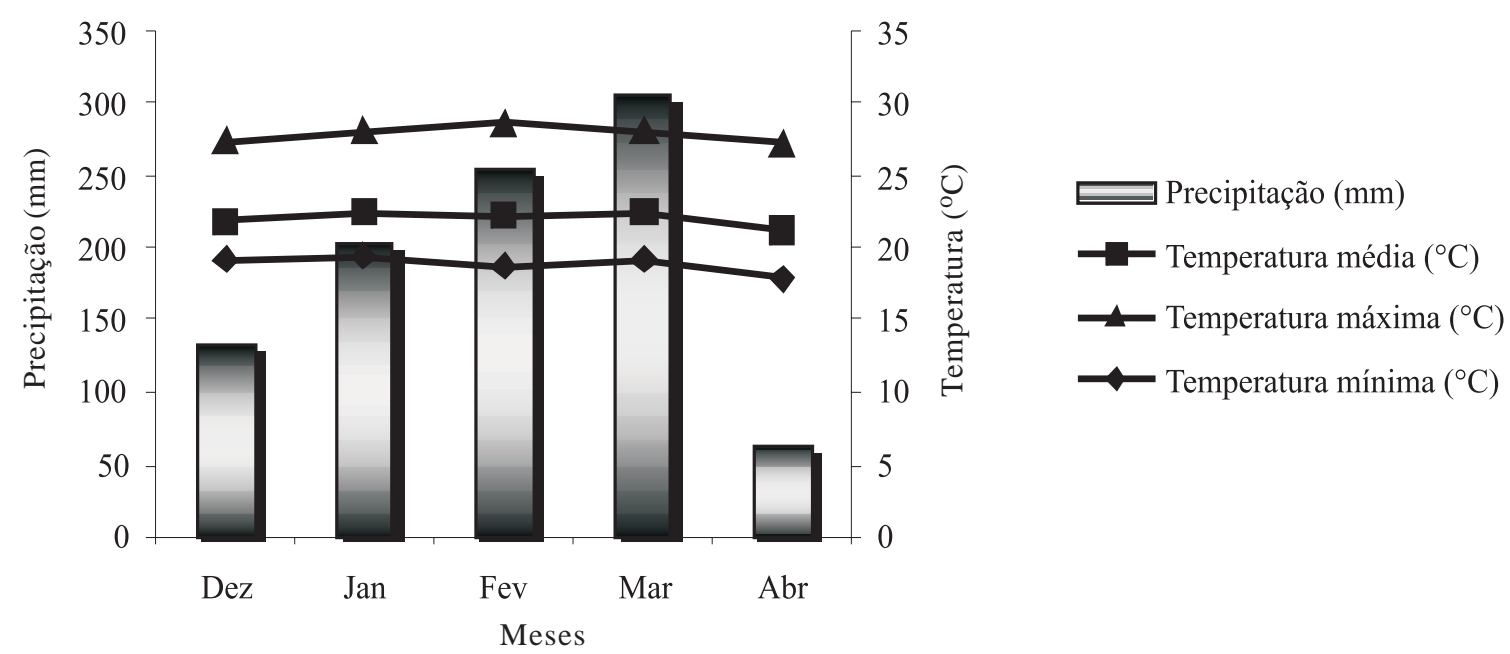

Figura 1 - Médias mensais das temperaturas máxima, média e mínima e da precipitação pluvial ao longo do período experimental. 
oscilando entre $22^{\circ} \mathrm{C}$ e $15^{\circ} \mathrm{C}$, respectivamente, para as médias de máxima e mínima (Figura 1).

O solo local é classificado como Argissolo vermelhoamarelo, de textura franco-argilosa (Embrapa, 1999), cujas características químicas por ocasião da instalação do experimento eram: $\mathrm{pH}\left(\mathrm{H}_{2} \mathrm{O}, 1: 2,5\right): 5,82 ; \mathrm{Al}: 0,00 \mathrm{cmol}_{C} \mathrm{dm}^{-3}$; $\mathrm{Ca}+\mathrm{Mg}: 4,24 \mathrm{cmol}_{\mathrm{C}} \mathrm{dm}^{-3} ; \mathrm{K}$ (Mehlich-1) : 24,0 $\mathrm{mg} \mathrm{dm}^{-3}$; $\mathrm{P}\left(\right.$ Mehlich-1) : $1,79 \mathrm{mg} \mathrm{dm}^{-3} ; \mathrm{H}+\mathrm{Al}: 6,14 \mathrm{cmol}_{\mathrm{C}} \mathrm{dm}^{-3}$, CTC : $10,44 \mathrm{cmol}_{\mathrm{C}} \mathrm{dm}^{-3} \mathrm{~V} \%: 41,2 \%$. Com base nesses valores, não houve necessidade alguma de calagem. O solo recebeu uma adubação de base de $110 \mathrm{~kg} \mathrm{ha}^{-1}$ de $\mathrm{P}_{2} \mathrm{O}_{5}$ na forma de superfosfato simples, aplicado de forma localizada na linha de semeadura em novembro de 2004. As adubações nitrogenadas e potássicas foram realizadas após o completo estabelecimento da pastagem no estádio de plântula, na quantidade de $50 \mathrm{~kg} \mathrm{ha}^{-1}$ de $\mathrm{N}$ utilizando-se como fonte o sulfato de amônio e $90 \mathrm{~kg} \mathrm{ha}^{-1}$ de $\mathrm{K}_{2} \mathrm{O}$ na forma de cloreto de potássio, parceladas em duas aplicações. As plantas foram semeadas em substrato orgânico comercial, em bandejas plásticas, mantidas em casa de vegetação e com irrigação diária até a data da transplantação das mudas para a área experimental (em torno de 35 dias da emergência). A área experimental foi limpa e preparada (enxada rotativa, divisão da área em unidades experimentais, correção, adubação fosfatada) para receber as plantas, que foram plantadas em unidades experimentais de $0,90 \mathrm{~m}^{2}(1,20 \mathrm{~m} \times$ 0,75 m). Cada unidade experimental continha 35 plantas arranjadas segundo um espaçamento de $20 \mathrm{~cm}$ entre plantas e $40 \mathrm{~cm}$ entre linhas.

Foram avaliadas duas alturas de corte ( 25 e $50 \mathrm{~cm}$ ) e três intervalos de corte (correspondentes ao período de tempo necessário para o surgimento de duas, três e quatro folhas por perfilho). Os tratamentos experimentais corresponderam à combinação entre os níveis desses dois fatores, os quais foram alocados às unidades experimentais (parcelas) segundo um arranjo fatorial $2 \times 3$ (altura de corte e intervalo de corte) e um delineamento de blocos completos casualizados, com três repetições. Como a frequência de corte foi diferente entre as combinações (Tabela 1 ), em cada um dos blocos o número de unidades de observação foi planejado em função do número esperado de cortes durante o período experimental, sendo igual a quatro, três e duas unidades de observação para as frequências de corte de duas, três e quatro folhas por perfilho, respectivamente, totalizando 54 unidades de observação.

O monitoramento do aparecimento de folhas nos perfilhos foi feito em dois perfilhos marcados por parcela, com avaliações duas vezes por semana. Quando a média da combinação entre altura e intervalo de corte, para cada unidade de avaliação, independentemente dos blocos, atingia o número de folhas surgidas predeterminado (duas, três e quatro folhas surgidas por perfilho), eram realizados os cortes e a data registrada. As medidas de altura do dossel foram realizadas utilizando-se uma régua, tomando-se três alturas em cada parcela. A altura em cada ponto correspondeu à altura da curvatura das folhas em torno da régua, e a média desses pontos representou a altura média do dossel antes do corte.

As características morfogênicas e estruturais foram avaliadas duas vezes por semana em dois perfilhos por unidade de observação, identificados aleatoriamente em duas das 35 plantas existentes. Esses perfilhos foram identificados com fios plásticos coloridos e, para melhor visualização no campo, foram fixadas hastes de arame com fita colorida ao lado de cada perfilho monitorado. Foram mensurados os comprimentos das lâminas foliares em expansão, expandidas e da parte verde das lâminas foliares senescentes, além do comprimento do pseudocolmo (altura do solo até a lígula da última folha expandida). Além disso, foram registradas todas as folhas novas surgidas durante cada período de avaliação. A partir dessas informações, foram calculadas as seguintes variáveis:

- taxa de aparecimento foliar (TApF, folha/perfilho.dia): relação entre o número de folhas surgidas por perfilho e o número de dias do período de avaliação;

- filocrono (FILOC, dias/folha.perfilho): inverso da taxa de aparecimento foliar;

- taxa de alongamento foliar (TAlF, cm/perfilho.dia): relação entre o somatório de todo alongamento das lâminas foliares (cm) e o número de dias do período de avaliação;

Tabela 1 - Data da combinação entre altura e intervalo de cortes

\begin{tabular}{ccccc}
\hline $\begin{array}{c}\text { Altura de corte } \\
(\mathrm{cm})\end{array}$ & $\begin{array}{c}\mathrm{N}^{0} \\
\text { folhas }\end{array}$ & 1 & 2 & Corte \\
\cline { 3 - 5 } 25 & 2 & $31 / 12 / 2004$ & $25 / 1 / 2005$ & $22 / 2 / 2005$ \\
50 & 2 & $28 / 12 / 2004$ & $25 / 1 / 2005$ & $25 / 2 / 2005$ \\
25 & 3 & $7 / 1 / 2005$ & $22 / 2 / 2005$ & $1 / 4 / 2005$ \\
50 & 3 & $7 / 1 / 2005$ & $22 / 2 / 2005$ & $1 / 4 / 2005$ \\
25 & 4 & $21 / 1 / 2005$ & $11 / 3 / 2005$ & $8 / 4 / 2005$ \\
50 & 4 & $14 / 1 / 2005$ & $18 / 3 / 2005$ & \\
\hline
\end{tabular}


- taxa de alongamento do colmo (TAlC, cm/ perfilho.dia): relação entre a diferença do comprimento do pseudocolmo no final e no início e o número de dias do período de avaliação;

- comprimento final das lâminas foliares ( $\mathrm{CFiF}, \mathrm{cm})$ : comprimento médio das lâminas foliares de todas as folhas expandidas presentes em um perfilho, mensuradas do ápice foliar até sua lígula;

- número de folhas vivas por perfilho (NFV): média do número de folhas em expansão e expandidas por perfilho durante o período de avaliação, excetuando-se as folhas que apresentassem mais de $50 \%$ do comprimento de seu limbo senescido;

- duração de vida das folhas (DVF, dias): estimada pela equação proposta por Lemaire \& Chapman (1996): DVF $=$ NFV $\times$ FILOC, haja vista que, devido aos cortes freqüentes, não foi possível calcular diretamente com os dados coletados no campo;

- taxa de senescência das lâminas foliares (TSF, cm/ perfilho.dia): relação entre o somatório dos comprimentos senescidos das lâminas foliares presentes no perfilho e o número de dias do período de avaliação.

Foi também avaliado o processo de perfilhamento utilizando-se duas touceiras escolhidas de forma aleatória por parcela. Inicialmente, todos os perfilhos de cada touceira foram marcados usando fios plásticos coloridos e, a cada 30 dias, uma nova contagem era realizada e novos perfilhos marcados com uma cor nova, caracterizando as gerações de perfilhos. Os perfilhos novos e os mortos eram contabilizados, obtendo-se o número total de perfilhos, em perfilhos/planta. Com os dados, foram calculadas as taxas de aparecimento (TApP), mortalidade (TMoP) e sobrevivência (TSoP) de perfilhos (perfilhos/perfilho.dia), segundo Carvalho et al. (2000).

Para avaliação da massa de forragem, coletou-se a biomassa aérea de quatro plantas por parcela (acima da altura de corte). A biomassa foi separada em lâminas foliares, colmo (colmo + bainhas foliares) e material morto, pesada e levada à estufa de ventilação forçada a $65^{\circ} \mathrm{C}$ por 72 horas, quando foi pesada novamente. Em função de como foram coletadas as amostras, os dados de massa de forragem podem também ser considerados como de acúmulo de forragem, e foram utilizados para calcular o acúmulo de lâminas foliares, colmos e material morto (MSM) $\mathrm{em} g / \mathrm{m}^{2}$.

Os dados foram submetidos à análise de variância utilizando-se o procedimento GLM do pacote estatístico SAS (SAS, 1996). A comparação de médias, quando necessária, foi realizada por meio de contrastes apropriados, tanto para os efeitos principais de altura e intervalo de corte quanto para os efeitos da interação entre esses fatores, adotando-se nível de significância de 5\%.

\section{Resultados e Discussão}

A taxa de aparecimento foliar (TApF) foi afetada $(\mathrm{P}<0,0001)$ pela interação altura de corte $\times$ intervalo de corte $\times$ corte. Lopes (2006) observou que a TApF tende a diminuir durante o processo de crescimento das plantas. Esse comportamento também foi observado neste experimento (Tabela 2), em que a TApF diminuiu com a redução do intervalo de desfolhação (aumento no número de folhas surgidas por perfilho) no primeiro corte. Na verdade, a taxa de iniciação das folhas no meristema apical (plastocrono) permanece constante em função da temperatura, mas, com o aumento do comprimento da bainha de folhas sucessivas em gramíneas eretas, eleva-se o tempo para o surgimento das folhas acima do cartucho e, consequentemente, ocorre diminuição da taxa de aparecimento foliar (Lemaire \& Chapman, 1996; Duru \& Ducrocq, 2000). Nos demais cortes não houve diferença entre as frequências de corte avaliadas, exceto para a altura de corte de $25 \mathrm{~cm}$ e o intervalo de três folhas surgidas por perfilho.

O filocrono foi afetado $(\mathrm{P}<0,0001)$ pela interação altura de corte $\times$ intervalo de corte $\times$ corte. Houve aumento do filocrono quando a intensidade de corte de $50 \mathrm{~cm}$ foi combinada ao intervalo de corte de duas folhas surgidas por perfilho nos cortes três e quatro, em comparação à altura de corte de $25 \mathrm{~cm}$ combinada ao intervalo de duas folhas surgidas por perfilho. O filocrono é resultante do inverso da TApF e está relacionado ao intervalo de tempo entre o aparecimento de duas folhas sucessivas. Foi observada relação inversa entre filocrono e TAlF (Tabela 2). Sbrissia (2008), trabalhando com capim-marandu submetido à lotação contínua, também relatou o mesmo comportamento entre filocrono e TAlF. Alguns autores mostraram que o aumento no comprimento da bainha foliar resulta em maiores valores de filocrono (Wilson \& Laidlaw, 1985; Skinner \& Nelson,1995), uma vez que o tempo necessário para a visualização da nova folha emergente pode ser atrasado, segundo uma relação básica estabelecida pelo comprimento das bainhas que envolvem o meristema apical e a taxa de alongamento foliar. A taxa de alongamento foliar (TAlF) foi afetada $(\mathrm{P}<0,0001)$ pela interação intervalo de corte $\times$ altura de corte $\times$ corte. A taxa de alongamento foliar parece ser a variável morfogênica que, isoladamente, mais se correlaciona diretamente com a massa seca de forragem (Horst et al., 1978) e é afetada de diversas formas pelos fatores de ambiente e de manejo. A TAlF diminuiu 
com a redução do intervalo de desfolhação (aumento no número de folhas surgidas por perfilho) (Tabela 2), provavelmente em decorrência da elevação do meristema apical resultante do processo de alongamento de colmos, condição necessária para a emissão de novas folhas em ambiente com luz, o que encurtou a distância que as novas lâminas deveriam percorrer até emergir do pseudocolmo (Gomide \& Gomide (2000).

A taxa de senescência foliar (TSeF) foi influenciada pela interação intervalo $\times$ altura $\times$ corte $(\mathrm{P}<0,0147)$. Maior TSeF foi observada quando a altura de corte de $50 \mathrm{~cm}$ foi combinada ao intervalo de corte de três folhas surgidas por perfilho, comparativamente à combinação da altura de corte $25 \mathrm{~cm}$ e número de três folhas surgidas por perfilho no corte 2. Para a altura de corte de $25 \mathrm{~cm}$, não houve variação em TSeF para as frequências de corte avaliadas, mas, para a altura de corte de $50 \mathrm{~cm}$, a TSeF foi maior para o número de três folhas surgidas por perfilho.

Nesta pesquisa, a TSeF (Tabela 2) e a TAlC (Figura 2 e 3) tenderam a aumentar com a diminuição da frequência de corte de 2 para 3 folhas surgidas por perfilho, corroborando os resultados de Lopes (2006) para capim-mombaça submetido a procedimento análogo de avaliação. Esse fato sugere que, idealmente, o corte do capim-tanzânia deveria ser feito quando do surgimento de 2 a 3 folhas por perfilho, condição em que o padrão de acúmulo de matéria seca parece ter sido modificado, reduzindo o acúmulo de folhas e aumentando o acúmulo de colmos e de material morto. O aumento no intervalo e/ou na altura de corte pode controlar o alongamento de colmos, fração indesejável e de composição bromatológica inferior àquela de lâminas foliares (Bueno, 2003), de baixo valor nutritivo (Difante, 2009), mas deve ser feito dentro dos limites de tolerância e resistência da planta à desfolhação, de forma a não comprometer a persistência do pasto.

A interação intervalo $\times$ altura $\times$ corte influenciou $(\mathrm{P}<0,0001)$ a duração de vida da folha (DVF), que foi menor na altura de corte de $25 \mathrm{~cm}$ em comparação à de $50 \mathrm{~cm}$ (Tabela 2), o que sugere maior renovação de tecidos sob condições de desfolhação mais severa (Sbrissia, 2008). Como o filocrono não variou com as alturas de corte avaliadas, a menor DVF para a altura de corte de $25 \mathrm{~cm}$ refletiu o menor número de folhas vivas por perfilho (NFV) sob aquela condição, exceção feita no primeiro corte (Tabela 3). Essas reduções em DVF e NFV indicam aumento da renovação de tecidos para a altura de corte de $25 \mathrm{~cm}$ em comparação à de $50 \mathrm{~cm}$.

A taxa de alongamento de colmos (TAlC) não foi afetada pela frequência de corte $(\mathrm{P}=0,4823)$, pela altura de corte $(\mathrm{P}=0,3154)$ nem pelas interações altura $\times$ intervalo de corte

Tabela 2 - Características morfogênicas do capim-tanzânia em duas alturas de corte e três intervalos de corte (médias de quatro cortes)

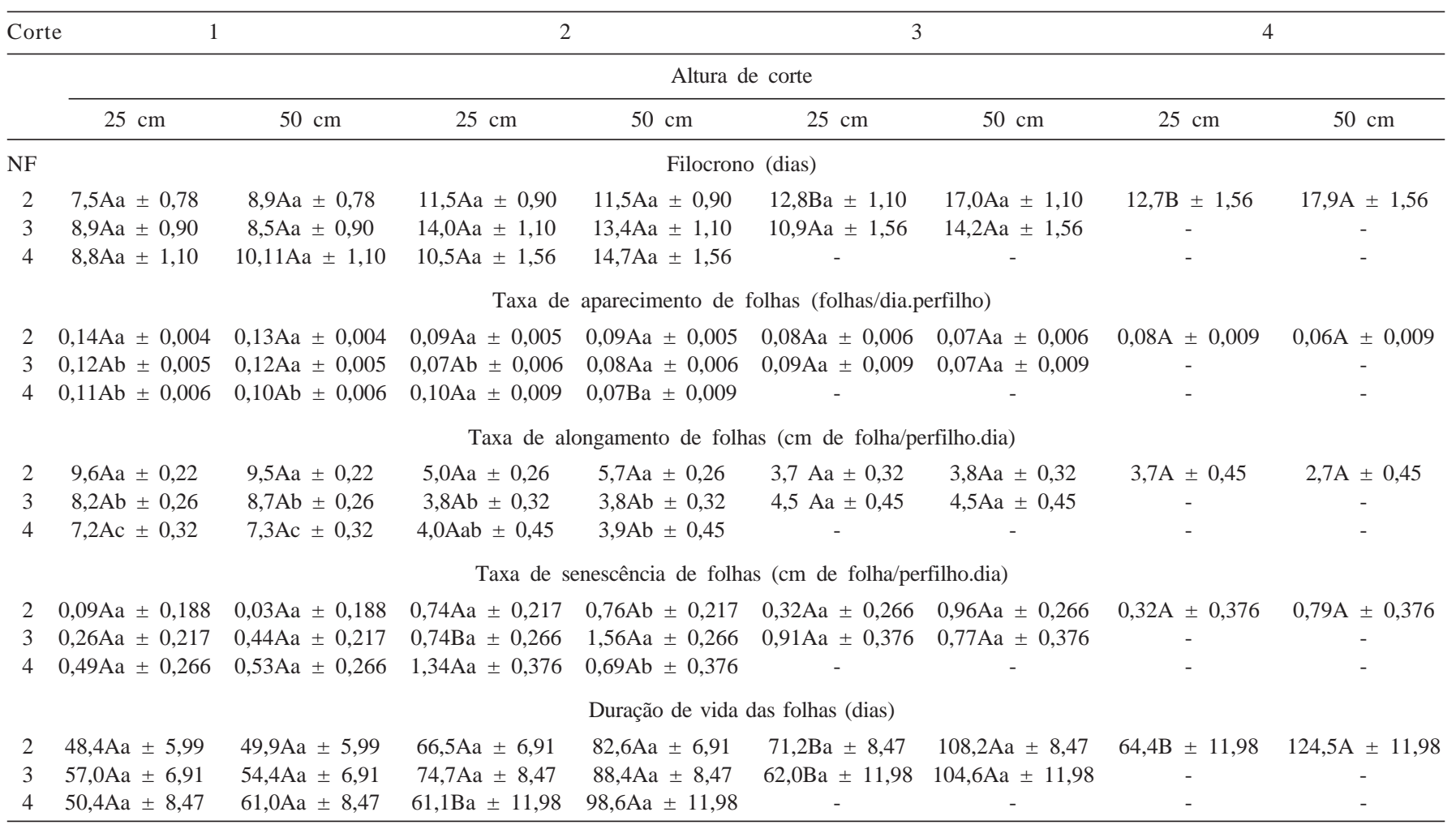

$\mathrm{NF}=$ número de folhas surgidas.

* Letras maiúsculas diferentes na linha, dentro de cortes, e minúsculas na coluna, diferem entre si pelo teste t $(\mathrm{P}<0,05)$. 

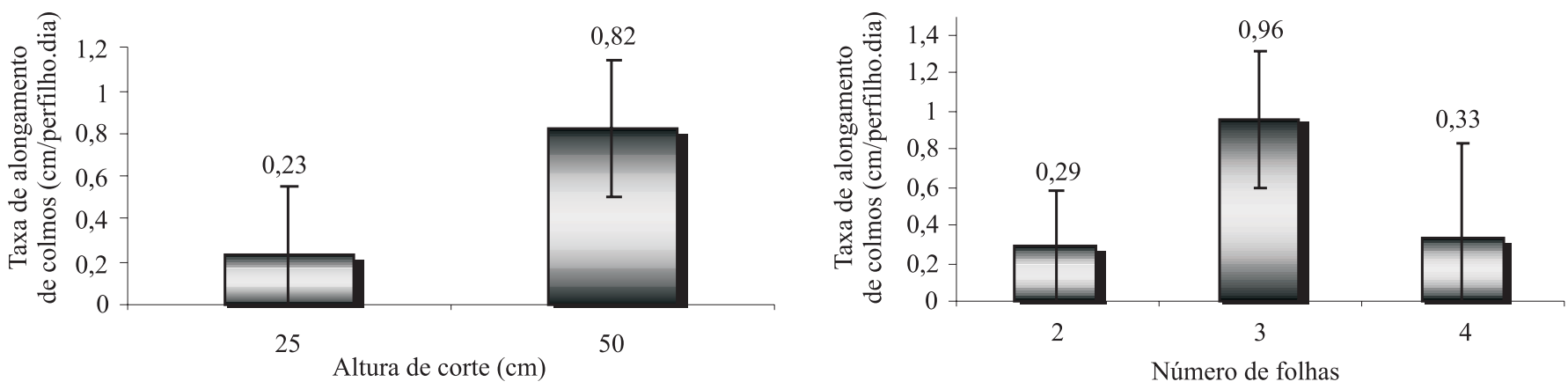

Figura 2 - Taxa de alongamento de colmos em capim-tanzânia submetido a duas alturas (25 e 50 cm) e a três intervalos de corte (duas, três e quatro folhas surgidas por perfilho).

Tabela 3 - Características estruturais do capim-tanzânia em duas alturas, três intervalos de corte e quatro cortes

\begin{tabular}{|c|c|c|c|c|c|c|c|c|}
\hline \multirow[t]{3}{*}{ Corte } & \multicolumn{2}{|c|}{1} & \multicolumn{2}{|c|}{2} & \multicolumn{2}{|c|}{3} & \multicolumn{2}{|c|}{4} \\
\hline & \multicolumn{8}{|c|}{ Altura de corte } \\
\hline & $25 \mathrm{~cm}$ & $50 \mathrm{~cm}$ & $25 \mathrm{~cm}$ & $50 \mathrm{~cm}$ & $25 \mathrm{~cm}$ & $50 \mathrm{~cm}$ & $25 \mathrm{~cm}$ & $50 \mathrm{~cm}$ \\
\hline NF & \multicolumn{8}{|c|}{ Comprimento de lâmina foliar $(\mathrm{cm})$} \\
\hline 2 & $32,6 \mathrm{Bb} \pm 1,18$ & 44,5 Aа $\pm 1,18$ & $23,0 \mathrm{Bb} \pm 1,37$ & 38,6 Aa $\pm 1,37$ & $20,0 \mathrm{Bb} \pm 1,68$ & $30,1 \mathrm{Aa} \pm 1,68$ & $22,1 \mathrm{~A} \pm 2,37$ & $28,3 \mathrm{~A} \pm 2,37$ \\
\hline 3 & $37,5 \mathrm{Ba} \pm 1,37$ & 48,0 Aа $\pm 1,37$ & $26,1 \mathrm{Bab} \pm 1,68$ & 40,6 Аа $\pm 1,68$ & $30,3 \mathrm{Aa} \pm 2,37$ & 34,0 Aа $\pm 2,37$ & - & - \\
\hline 4 & 38,9 Ва $\pm 1,68$ & 48,7Аа $\pm 1,68$ & $29,0 \mathrm{Ba} \pm 2,37$ & 37,3 Aа $\pm 2,37$ & - & - & - & - \\
\hline & \multicolumn{8}{|c|}{ Número de folhas vivas (folhas/perfilho) } \\
\hline 2 & 6,5 Aа $\pm 0,22$ & $5,7 \mathrm{Bb} \pm 0,22$ & $5,8 \mathrm{Ba} \pm 0,26$ & 7,2Аа $\pm 0,26$ & 5,7 Aа $\pm 0,31$ & 6,3 Aа $\pm 0,31$ & $5,0 \mathrm{~B} \pm 0,44$ & $7,0 \mathrm{~A} \pm 0,44$ \\
\hline 3 & 6,4Аa $\pm 0,26$ & 6,4Aa $\pm 0,26$ & $5,3 \mathrm{Ba} \pm 0,31$ & 6,6Аa $\pm 0,31$ & $5,7 \mathrm{Ba} \pm 0,44$ & 7,3Аа $\pm 0,44$ & - & - \\
\hline 4 & 5,7 Aa $\pm 0,31$ & $6,1 \mathrm{Aab} \pm 0,31$ & $5,8 \mathrm{Aa} \pm 0,44$ & 6,6 Aa $\pm 0,44$ & - & - & - & - \\
\hline & \multicolumn{8}{|c|}{ Altura pré-desfolhação (cm) } \\
\hline 2 & $71 \mathrm{Ab} \pm 1,7$ & $74 \mathrm{Ac} \pm 1,7$ & $62 \mathrm{Bb} \pm 2,0$ & $88 \mathrm{Ac} \pm 2,0$ & $54 \mathrm{Bb} \pm 2,5$ & $93 \mathrm{Ab} \pm 2,5$ & $75 B \pm 3,5$ & $125 \mathrm{~A} \pm 3,5$ \\
\hline 3 & $67 \mathrm{Bb} \pm 2,0$ & $83 \mathrm{Ab} \pm 2,0$ & $67 \mathrm{Bb} \pm 2,5$ & $99 \mathrm{Ab} \pm 2,5$ & $90 \mathrm{Ba} \pm 3,5$ & 119 Aа \pm 3,5 & - & - \\
\hline 4 & 99 Aа $\pm 2,5$ & $98 \mathrm{Aa} \pm 2,8$ & $80 \mathrm{Ba} \pm 3,5$ & $142 \mathrm{Aa} \pm 3,5$ & - & - & - & - \\
\hline
\end{tabular}

$\mathrm{NF}=$ número de folhas surgidas.

* Letras maiúsculas diferentes na linha, dentro de cortes, e minúsculas na coluna diferem $(\mathrm{P}<0,05)$ entre si pelo teste $t$.

$(\mathrm{P}=0,3566)$ e altura $\times$ intervalo $\times$ corte $(\mathrm{P}=0,6327)$. Foram observados maiores valores de TAlC para a altura de corte de $50 \mathrm{~cm}$ em relação àquela de $25 \mathrm{~cm}$ (Figura 2), aumento esse que pode ter ocasionado a diferença na altura prédesfolhação (Tabela 3).

Observou-se tendência de menor taxa de alongamento de colmos para a frequência de corte de duas folhas surgidas por perfilho (Figura 2), apesar de não terem sido registradas diferenças entre as frequências avaliadas, consequência do alto erro-padrão associado às medições $( \pm 0,29 ; \pm 0,36$; $\pm 0,49$ para duas, três e quatro folhas surgidas, respectivamente). As informações (Figura 2) demonstram que a frequência de corte é importante no controle do desenvolvimento de colmos e da estrutura do dossel forrageiro.

Embora o alongamento de colmos favoreça o aumento da produção de massa seca (Tabela 4), ele pode influenciar negativamente a eficiência de pastejo e o valor nutritivo da forragem produzida (Bueno, 2003; Difante, 2009; Sarmento,
2007), além de aumentar o intervalo de aparecimento de folhas, ou seja, o filocrono (Tabela 2). De acordo com Santos (2004), um dos grandes problemas no manejo do capim-tanzânia é o aumento da participação dos colmos com a chegada da época de florescimento. Esse problema pode ser estendido a outras espécies de clima tropical, pois, da mesma forma, ocorre o processo de alongamento de colmos na época de florescimento, variando apenas a altura de sua ocorrência.

O comprimento final das folhas (CFiF) foi afetado $(\mathrm{P}<0,0001)$ pela interação intervalo $\times$ altura $\times$ corte. De acordo com Lemaire \& Chapman (1996), o CFiF é uma característica plástica responsiva à altura de desfolhação, considerada uma estratégia morfológica de escape da planta ao pastejo. De modo geral, os menores valores de CFiF foram registrados para a altura de corte de $25 \mathrm{~cm}$ (Tabela 3). Isso porque desfolhações mais intensas resultaram em diminuição do comprimento da bainha foliar, 
provavelmente consequência de redução da fase de multiplicação celular, acarretando em menor comprimento final da lâmina, como demonstrado por Duru \& Ducrocq (2000), sendo o inverso também verdadeiro. Gomide \& Gomide (2000) observaram maior comprimento das folhas de nível de inserção intermediário em cultivares de $P$. maximum devido ao maior comprimento do pseudocolmo. As lâminas de mais elevado nível de inserção, no entanto, voltaram a ter maior TApF e menor comprimento final, em virtude da elevação do meristema apical, resultante do processo de alonga-mento do colmo, encurtando a distância que a lâmina deveria percorrer até emergir do pseudocolmo (Tabelas 2 e 3). Esse padrão de resposta foi também registrado por Silveira (2007), em experimento no qual foram avaliaram oito cultivares do gênero Brachiaria e dois do gênero Panicum.

O número de folhas vivas por perfilho (NFV) foi afetado $(\mathrm{P}<0,0001)$ pela interação intervalo $\times$ altura $\times$ corte. $\mathrm{O}$ número máximo de folhas vivas por perfilho é atingido quando se inicia o equilíbrio entre a taxas de aparecimento e de senescência das folhas. Esse fato foi verificado neste experimento, em que foi registrada relação inversa entre a taxa de aparecimento e a de senescência de folhas, indicativo de certa estabilidade no número de folhas vivas por perfilho (Tabelas 2 e 3). O número máximo de folhas vivas por perfilho é uma constante genotípica (Davies, 1988) e pode ser calculado como a duração de vida das folhas expressa em número de intervalos de aparecimento de folhas, ou seja, em número de filocronos. O número de folhas vivas é influenciado pela TApF e pela DVF (Tabelas 2 e 3) e, de acordo com Nabinger (1998), é determinado geneticamente e pouco variável, independentemente do manejo aplicado ou das condições edafo-climáticas vigentes.

A altura pré-desfolhação foi afetada $(\mathrm{P}<0,0001)$ pela interação intervalo $\times$ intensidade $\times$ corte. A altura prédesfolhação aumentou quando o intervalo de corte passou de duas para quatro folhas surgidas por perfilho (Tabela 3), o que pode ter sido reflexo do aumento do intervalo entre cortes. Como plantas de hábito de crescimento ereto tendem a alongar o colmo para colocar as novas folhas no topo do dossel (Woledge, 1978), o aumento do intervalo de corte com a redução da frequência de desfolhação pode ter resultado no aumento da altura pré-desfolhação. A altura de corte de $50 \mathrm{~cm}$ apresentou altura pré-desfolhação superior àquela da altura de corte de $25 \mathrm{~cm}$. Lopes (2006) também reportou ocorrência semelhante para o capimmombaça manejado de forma análoga à deste experimento.

Recentemente, em trabalhos com gramíneas tropicais, tem sido verificada forte relação entre altura do dossel e sua IL na condição de pré-pastejo e, consequentemente, com o
IAF crítico (Carnevalli et al., 2006; Barbosa et al., 2007; Difante, 2005; Pedreira et al., 2007). Isso indica que a altura do dossel forrageiro pode ser usada como uma característica confiável para o controle do pastejo em lotação intermitente. A IL de 95\% é tida como momento a partir do qual plantas modificam sua dinâmica de acúmulo de matéria seca, reduzindo o acúmulo de lâminas foliares e aumentando rapidamente o acúmulo de colmos e de material morto (Da Silva \& Corsi, 2003).

Em capim-tanzânia, Mello \& Pedreira (2004), Barbosa et al. (2007) e Difante (2009) observaram que a IL de 95\% pelo dossel ocorreu com altura próxima de $70 \mathrm{~cm}$ e Carnevalli et al. (2006) relataram para o capim-mombaça alturas próximas de $90 \mathrm{~cm}$ nessa mesma condição de interceptação da luz incidente. Então, se 95\% IL é o momento ideal para interromper o processo de rebrotação das plantas forrageiras, para o capim-tanzânia esse momento estaria relacionado ao surgimento de duas folhas por perfilho (Tabela 3), pois nessa frequência de corte é que se encontrou altura média de $70 \mathrm{~cm}$ e que, teoricamente, houve o maior balanço positivo entre alongamento de folhas e senescência e menor alongamento de colmos. Cândido et al. (2006) concluíram que o período de descanso em pastagens de capim-tanzânia sob pastejo por ovinos não deveria exceder o tempo necessário para a expansão de 2,5 novas folhas por perfilho. Mello \& Pedreira (2004), em experimento com capim-tanzânia, concluíram que os IAF críticos medidos (condição para 95\% de IL) sugerem a necessidade de períodos de descanso relativamente curtos em pastos de capim-tanzânia submetidos a pastejo intensivo sob lotação rotacionada e irrigação.

A taxa de aparecimento de perfilhos (TApP, perfilhos/ perfilho.dia) não foi afetada pelo intervalo $(\mathrm{P}=0,4776)$, pela altura de corte $(\mathrm{P}=0,3585)$ nem pelas interações intervalo $\times$ altura de corte $(\mathrm{P}=0,3094)$, altura $\times$ período ( $\mathrm{P}=0,2636)$, intervalo de corte $\times$ período $(\mathrm{P}=0,1491)$. Houve, contudo, efeito do período de avaliação $(\mathrm{P}=0,0056)$. Os valores de TApP foram maiores no primeiro período (Figura 3). As altas precipitações podem ter favorecido o crescimento e o desenvolvimento das plantas, estimulando o perfilhamento. No período 2, a TApP diminuiu e, no último período, voltou a aumentar, atingindo valores semelhantes àqueles registrados durante o primeiro período de avaliação. A taxa de mortalidade de perfilhos (TMoP, perfilho/perfilho.dia) comportou-se de maneira semelhante à TApP, com efeito apenas do período de avaliação ( $\mathrm{P}=0,0103$ ). Também a TApP diminuiu ao longo do período experimental (Figura 3), enquanto a TMoP aumentou, provavelmente como consequência do equilíbrio que a planta tenta manter para manter estável a população de 
perfilhos. A precipitação foi outro fator que pode ter influenciado a TApP e TMoP. A taxa de sobrevivência de perfilhos (TSoP, perfilho/perfilho.dia) também comportou-se da mesma maneira que a TApP e a TMoP, com efeito apenas do período de avaliação ( $\mathrm{P}=0,0102)$. A TSoP foi semelhante durante o primeiro e segundo, mas diminuiu no terceiro e último períodos de avaliação (Tabela 4). Como a TSoP é a TMoP subtraída de uma unidade, o mesmo comportamento da TMoP foi observado para a TSoP, entretanto de forma inversa.

No segundo e terceiro períodos, a taxa de mortalidade foi maior que a de aparecimento (Figura 3) e a taxa de sobrevivência foi menor no terceiro período (Figura 4), indicando padrão intenso de renovação da população de perfilhos.

$\mathrm{O}$ acúmulo de lâminas foliares foi afetado $(\mathrm{P}=0,0005)$ pela interação intervalo $\times$ altura $\times$ corte. A maior MSLF ocorreu quando a altura de corte de $50 \mathrm{~cm}$ foi combinada ao número de quatro folhas surgidas por perfilho no corte 2 , em relação aos intervalos de corte de duas e três folhas surgidas por perfilho. No corte 3, foi observado o mesmo padrão de comportamento quando as alturas de corte de 25 e $50 \mathrm{~cm}$ foram combinadas ao intervalo de três folhas surgidas por perfilho, em comparação à frequência de duas folhas surgidas por perfilho. De acordo com Parsons \& Penning (1988), maiores frequências de desfolhação implicam menor tempo e maior vigor de rebrotação, em função da maior densidade populacional de perfilhos jovens, resultando em pastos mais baixos e com menor acúmulo de forragem no momento do corte, o inverso do que ocorre com as parcelas manejadas com menores frequências de desfolhação. Cano et al. (2004), em experimento com capim-tanzânia, concluíram que, independentemente da altura do dossel e do período de avaliação estudados, o valor nutritivo das lâminas foliares foi melhor que o observado para colmos + bainha, indicando que o manejo do pasto deve ser direcionado à contribuição da massa de forragem de folhas, desde que não comprometa a persistência do dossel forrageiro. O acúmulo de colmos foi afetado pela interação intervalo $\times$ altura $\times$ corte $(\mathrm{P}=0,0007)$. Não foram observadas grandes variações no acúmulo de colmos para as alturas e os intervalos de corte avaliados. O acúmulo de colmos só variou entre as alturas de corte no corte 2 e, para os intervalos de corte, foi menor para o intervalo de duas folhas surgidas por perfilho em comparação aos de três e quatro folhas surgidas por perfilho (Tabela 5), também no mesmo corte. O que pode ter acontecido é que o maior intervalo de corte, 64 dias, (Tabela 1) não foi longo o suficiente para que houvesse acúmulo significativo de colmos.

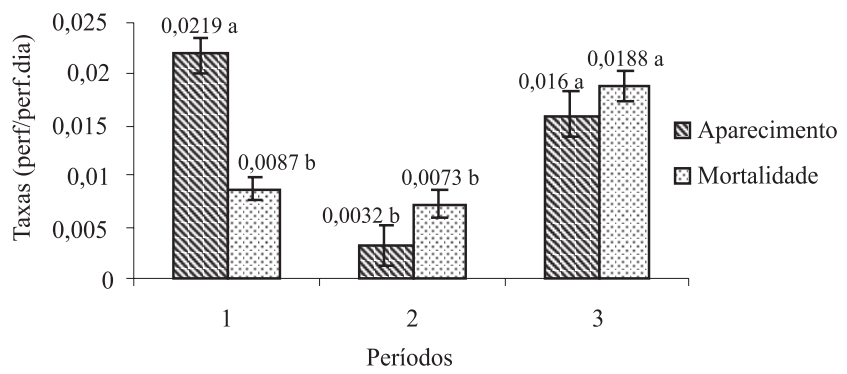

Figura 3 - Taxas de aparecimento e mortalidade de perfilhos (perfilho/perfilho.dia) nos três períodos de avaliação

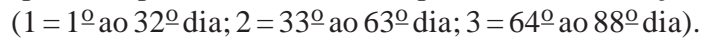

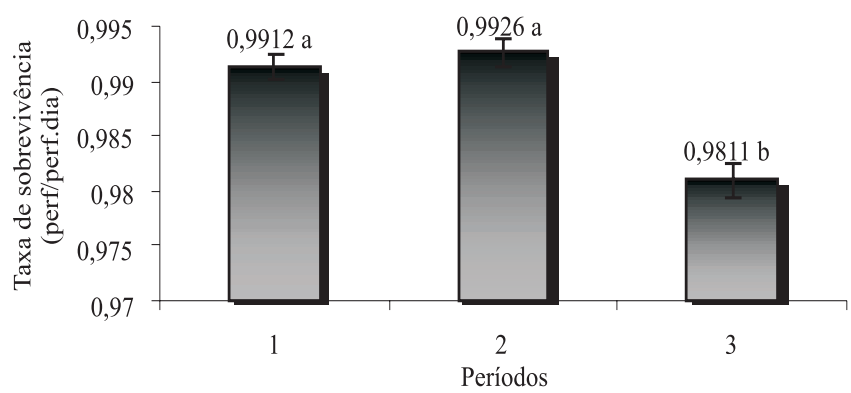

Figura 4 - Taxa de sobrevivência de perfilhos (perfilho/ perfilho.dia) nos três períodos de avaliação $\left(1=1^{\underline{0}}\right.$ ao

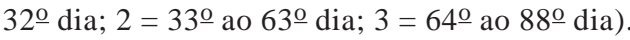

Tabela 4 - Acúmulo de lâminas foliares (g/m² de MS) em capim-tanzânia submetido a três intervalos de corte, duas alturas de corte e quatro cortes

\begin{tabular}{|c|c|c|c|c|c|c|c|c|}
\hline \multirow[t]{3}{*}{ Corte } & \multicolumn{2}{|r|}{1} & \multicolumn{2}{|c|}{2} & \multicolumn{2}{|l|}{3} & \multicolumn{2}{|c|}{4} \\
\hline & \multicolumn{8}{|c|}{ Altura de corte } \\
\hline & $25 \mathrm{~cm}$ & $50 \mathrm{~cm}$ & $25 \mathrm{~cm}$ & $50 \mathrm{~cm}$ & $25 \mathrm{~cm}$ & $50 \mathrm{~cm}$ & $25 \mathrm{~cm}$ & $50 \mathrm{~cm}$ \\
\hline \multicolumn{9}{|l|}{ NF } \\
\hline 2 & $334,6 \mathrm{Ab} \pm 43,42$ & $434,3 \mathrm{Ab} \pm 43,42$ & $318,7 \mathrm{Aa} \pm 50,13$ & $311,1 \mathrm{Ac} \pm 50,13$ & $189,6 \mathrm{Ab} \pm 61,40$ & $264,1 \mathrm{Ab} \pm 61,40$ & $184,7 \mathrm{~A} \pm 86,40$ & $401,9 \mathrm{~A} \pm 86,40$ \\
\hline 3 & $224,7 \mathrm{Bb} \pm 50,13$ & $576,9 \mathrm{Aa} \pm 50,13$ & $439,1 \mathrm{Aa} \pm 61,40$ & $520,1 \mathrm{Ab} \pm 61,40$ & $589,8 \mathrm{Aa} \pm 86,84$ & $538,0 \mathrm{Aa} \pm 86,40$ & - & - \\
\hline 4 & $510,4 \mathrm{Aa} \pm 61,40$ & $544,4 \mathrm{Aab} \pm 61,40$ & $320,8 \mathrm{Ba} \pm 86,84$ & $1085,6 \mathrm{Aa} \pm 86,84$ & - & - & - & - \\
\hline
\end{tabular}

$\mathrm{NF}=$ número de folhas surgidas.

* Letras maiúsculas diferentes na linha, dentro de cortes, e minúsculas na coluna diferem $(\mathrm{P}<0,05)$ entre si pelo teste t. 
Tabela 5 - Acúmulo de colmos (g/m² de MS) em capim-tanzânia submetido a três intervalos de corte, duas alturas de corte e quatro cortes

\begin{tabular}{|c|c|c|c|c|c|c|c|c|}
\hline \multirow[t]{3}{*}{ Corte } & \multicolumn{2}{|c|}{1} & \multicolumn{2}{|c|}{2} & \multicolumn{2}{|l|}{3} & \multicolumn{2}{|l|}{4} \\
\hline & \multicolumn{8}{|c|}{ Altura de corte } \\
\hline & $25 \mathrm{~cm}$ & $50 \mathrm{~cm}$ & $25 \mathrm{~cm}$ & $50 \mathrm{~cm}$ & $25 \mathrm{~cm}$ & $50 \mathrm{~cm}$ & $25 \mathrm{~cm}$ & $50 \mathrm{~cm}$ \\
\hline NF & & & & & & & & \\
\hline 2 & $41,3 \mathrm{Aa} \pm 50,04$ & $125,6 \mathrm{Aa} \pm 50,04$ & $49,7 \mathrm{Aa} \pm 57,78$ & $87,7 \mathrm{Ab} \pm 57,78$ & $35,6 \mathrm{Aa} \pm 70,77$ & $14,6 \mathrm{Aa} \pm 70,77$ & $45,4 \mathrm{~A} \pm 100,08$ & $6,5 \mathrm{~A} \pm 100,08$ \\
\hline 3 & $0,0 \mathrm{Ba} \pm 57,78$ & $190,1 \mathrm{Aa} \pm 57,78$ & $21,1 \mathrm{Aa} \pm 70,77$ & $166,9 \mathrm{Ab} \pm 70,77$ & $43,1 \mathrm{Aa} \pm 100,08$ & $149,1 \mathrm{Aa} \pm 100,08$ & - & - \\
\hline 4 & $97,2 \mathrm{Aa} \pm 70,77$ & $18,3 \mathrm{Aa} \pm 70,77$ & $5,8 \mathrm{Ba} \pm 100,08$ & $904,2 \mathrm{Aa} \pm 100,08$ & - & - & - & - \\
\hline
\end{tabular}

$\mathrm{NF}=$ número de folhas surgidas.

* Letras maiúsculas diferentes na linha, dentro de cortes, e minúsculas na coluna diferem $(\mathrm{P}<0,05)$ entre si pelo teste t.

O acúmulo de material morto (MSM) não foi afetado pelo intervalo $(\mathrm{P}=0,2389)$ nem pela altura corte $(\mathrm{P}=0,8101)$. Também não houve efeito das interações intervalo $\times$ altura de corte $(\mathrm{P}=0,1005)$ e intervalo $\times$ altura de corte $\times$ corte $(\mathrm{P}=0,5020)$.

\section{Conclusões}

O intervalo de corte no capim-tanzânia não deve exceder o tempo necessário para o aparecimento de duas a três folhas por perfilho. Tanto o intervalo quanto a altura de corte podem influenciar o acúmulo e a composição morfológica da forragem produzida, e sua importância relativa varia com a época do ano e o estádio fenológico das plantas.

\section{Literatura Citada}

ARONOVICH, S. O capim colonião e outros cultivares de Panicum maximum (Jacq.): Introdução e evolução do uso no Brasil. In: SIMPÓSIO SOBRE MANEJO DA PASTAGEM, 12, 1995, Piracicaba. Anais... Piracicaba: Fundação de Estudos Agrários "Luiz de Queiroz”, 1995. p.1-20.

BARBOSA, R.A.; NASCIMENTO JR., D.; EUCLIDES, V.P.B. et al. Capim-tanzânia submetido a combinações entre intensidade e frequência de pastejo. Pesquisa Agropecuária Brasileira, v.42, p.329-340, 2007.

BUENO, A.A.O. Características estruturais do dossel forrageiro, valor nutritivo e produção de forragem em pastos de capimMombaça submetidos a regimes de desfolhação intermitente. 124f. 2003. Dissertação (Mestrado em Agronomia - Ciência Animal e Pastagens) - Fundação de Estudos Agrários "Luiz de Queiroz”, Piracicaba, 2003.

CÂNDIDO, M.J.D.; DA SILVA, R.G.; NEIVA, J.N.M. et al. Fluxo de biomassa em capim-tanzânia pastejado por ovinos sob três períodos de descanso. Revista Brasileira de Zootecnia, v.35, n.6, p.2234-2242, 2006.

CANO, C.C.P.; CECATO, U.; CANTO, M.W. et al. Valor nutritivo do capim-tanzânia (Panicum maximum Jacq. cv. Tanzânia-1) pastejado em diferentes alturas. Revista Brasileira de Zootecnia, v.33, n.6, p.1959-1968, 2004 (supl. 2).

CARNEVALLI, R.A.; DA SILVA, S.C., OLIVEIRA, A.A. et al. Herbage production and grazing losses in Panicum maximum cv. Mombaça pastures under four grazing managements. Tropical Grasslands, v.40, n.3, 2006.

CARVALHO, C.A.B.; DA SILVA, S.C.; CARNEVALLI, R.A. et al. Perfilhamento e acúmulo de forragem em pastagens de Florakirk
(Cynodon spp.) manejadas em quatro alturas de pasto. Boletim da Indústria Animal, v.57, n.1, p.39-51, 2000.

DA SILVA, S.C.; CORSI, M. Manejo do pastejo. In: SIMPÓSIO SOBRE MANEJO DA PASTAGEM, 20., 2003, Piracicaba, Anais... Piracicaba: Fundação de Estudos Agrários "Luiz de Queiroz”, 2003. p.155-186.

DA SILVA, S.C.; BUENO, A.A.O.; CARNEVALLI, R.A. et al. Sward structural characteristics and herbage accumulation of Panicum maximum cv. Mombaça subjected to rotational stocking managements. Scientia Agricola, v.66, n.1, p.8-19, 2009.

DAVIES, A. The regrowth of grass sward. In: JONES, M.B., LAZENBY,A. (Eds.) The grass crop: the physiological basis of production. London: Chapman \& Hall, 1988. p.85-127.

DEREGIBUS, V.A.; SANCHEZ, R.A.; CASAL, J.J. Effects of light quality on tiller production in Lolium spp. Plant Physiology, v.72, p.900-912, 1983.

DIFANTE, G.S.; EUCLIDES, V.P.B.; NASCIMENTO JR., D. et al. Ingestive behaviour, herbage intake and grazing efficiency of beef cattle steers on Tanzania guineagrass subjected to rotational stocking managements. Revista Brasileira de Zootecnia, v.38, n.6, p.1001-1008, 2009.

DURU, M; DUCROCQ, H. Growth and senescence of the successive grass leaves o a tiller ontogenic development and effect of temperature. Annals of Botany, v.85, p.635-643, 2000.

EMBRAPA - EMPRESA BRASILEIRA DE PESQUISA AGROPECUÁRIA. Sistema brasileiro de classificação de solos. Brasília: EMBRAPA, 1999. 412p. (Produção de Informação).

FULKERSON, W.J.; SLACK, K. Leaf number as a criterion for determining defoliation time for Lolium perenne: 2. Effect of defoliation frequency and height. Grass and forage Science, v.50, p.16-20, 1995.

GOMIDE, J.A. Morfogênese e análise de crescimento de gramíneas tropicais. In: SIMPÓSIO INTERNACIONAL SOBRE PRODUÇÃO ANIMAL EM PASTEJO. 1997, Viçosa, MG. Anais... Viçosa, MG: 1997. 471p.

GOMIDE, C.A.M.; GOMIDE, J.A. Morfogênese de cultivares de Panicum maximum Jacq. Revista Brasileira de Zootecnia, v.29, n.2, p.341-348, 2000.

GRANT, S.A.; BARTHRAM, G.T.; TORVEL, L. et al. Comparison of herbage production under continuous stocking and intermittent grazing. Grass and Forage Science, v.43, n.1, p.29-39, 1988.

HORST, G.L.; NELSON, C.J.; ASAY, K.H. Relationship of leaf elongation to forage yield of tall fescue genotypes. Crop Science, v.18, p.715-719, 1978.

LEMAIRE, G.; CHAPMAN, D. Tissue flows in grazed plant communities. In: HODGSON, J.; ILliUS, A.W. (Eds.) The ecology and management of grazing systems. Wallingford: Cab International, 1996. p.3-36.

LOPES, B.A. Características morfofisiológicas e acumulo de forragem em capim-mombaça submetido a regimes de desfolhação. 2006. 188f. Tese (Doutorado em Zootecnia) Universidade Federal de Viçosa, Viçosa, MG, 2006. 
MELLO, A.C.L.; PEDREIRA, C.G.S. Respostas morfológicas do capim-tanzânia (Panicum maximum Jacq. cv. Tanzânia-1) irrigado à intensidade de desfolha sob lotação rotacionada. Revista Brasileira de Zootecnia, v.33, n.2, p.282-289, 2004.

NABINGER, C. Princípios de manejo e produtividade de pastagens. In: CICLO DE PALESTRAS EM PRODUÇÃO E MANEJO DE BOVINOS DE CORTE, 3., 1998, Canoa. Anais... Canoa: Editora da ULBRA, 1998. p.54-107.

PARSONS, A.J.; PENNING, P.D. The effect of the duration of regrowth on photosynthesis, leaf death and the average rate of growth in a rotationally grazed sward. Grass and Forage Science, v.43, p.15-27, 1988.

PEDREIRA, B.C.; PEDREIRA, C.G.S.; Da SILVA, S.C. Estrutura do dossel e acúmulo de forragem de Brachiaria brizantha cultivar Xaraés em resposta a estratégias de pastejo. Pesquisa Agropecuária Brasileira, v.42, p.281-287, 2007.

SANTOS, P.M.; BALSALOBRE, A.A.M.; CORSI, M. et al. Características morfogenéticas e taxa de acúmulo de forragem do capim-mombaça submetido a três intervalos de pastejo. Revista Brasileira de Zootecnia, v.33, n.4, p.843-851, 2004.

SARMENTO, D. O. L. Produção, composição morfológica e valor nutritivo da forragem em pastos de Brachiaria brizantha (Hochst ex A. Rich) Stapf cv marandu submetidis a estratégias de pastejo rotativo por bovinos de corte.
2007. 144f. Tese (Doutorado em Agronomia - Ciência Animal e Pastagens) - Escola Superior de Agricultura Luiz de Queiroz, Piracicaba, 2007.

SATTLER, R.; RUTISHAUSER, R. The fundamental relevance of morphology and morphogenesis to plant research. Annals of Botany, v.80, p.571-582, 1997.

SBRISSIA, A.F.; DA SILVA, S.C. Compensação tamanho/densidade populacional de perfilhos em pastos de capim-marandu. Revista Brasileira de Zootecnia, v.37, n.1, p.35-47, 2008.

SILVEIRA, M.C.T. Caracterização morfogênica de oito cultivares do gênero Brachiaria e dois do gênero Panicum. 2007. 83f. Dissertação (Mestrado em Zootecnia) - Universidade Federal de Viçosa, Viçosa, MG, 2007.

SKINNER, R.H.; NELSON, C.J. Elongation of the grass leaf and its relationship to the phyllochron. Crop Science, v.35, n.1, p.4-10, 1995.

STATISTICAL ANALYSIS SYSTEM - SAS. SAS/STAT User's guide statistics. Versão 6. 4.ed. Cary: SAS Institute, 1996. v.1,2.

WILSON, R.E.; LAIDLAW, A.S. The role of the sheath tube in the development of expanding leaves in perennial ryegrass. Annals of Applied Biology, v.106, p.385-391, 1985.

WOLEDGE, J. The effect of shading during vegetative and reprodutive growth on the photosynthetic capacity of leaves in a grass sward. Annals of Botany, v.42, p.1085-1089, 1978. 